\title{
LA CUESTIÓN TEOLÓGICO-POLÍTICA EN LA LEGITIMACIÓN DEL FRANQUISMO. PREMISAS CONCEPTUALES Y EVOLUCIÓN HISTÓRICA*
}

\author{
POR \\ JUAN CARLOS SALES ${ }^{1}$ \\ Universitat Jaume I
}

\section{RESUMEN}

Este ensayo de análisis conceptual pretende problematizar algunas de las corrientes teológico-políticas españolas y europeas con el fin de clasificar los procesos del franquismo en relación a la legitimación de su estatuto político. Las intersecciones en el franquismo entre política y religión, más allá de cualquier supuesta vinculación clara y precisa, revisten de una nebulosa problemática precisamente por establecerse como un sistema político pretendidamente influido por la teología católica, desde la que obtiene mayormente su legitimación. Sin una pertinente diferenciación categorial, por tanto, se cae en el riesgo de confundir la naturaleza misma del franquismo y la relación con su etapa histórica. Solo tras este ejercicio de demarcación se podrá avanzar hacia diagnósticos que permitan comprender el complejo cambio de paradigma de las realidades políticas que intervienen a lo largo del Régimen.

PALABRAS CLAVE: franquismo; teología política; catolicismo; C. Schmitt; legitimación.

\section{THE POLITICAL-THEOLOGICAL THEMA IN THE LEGITIMATION OF THE FRANCOISM. CONCEPTUAL PREMISES AND HISTORICAL EVOLUTION}

\begin{abstract}
This essay of conceptual analysis aims to problematize some theological-political trends in order to better classify parts of the processes in Francoism, in relation with its political legitimacy. The crossroads between politics and religion, beyond any supposed natural relation, represents in the Francoist regime an intense problematic, due to the connections and influences of the Catholicism. Thus, without a categorical differentiation it would be easier to fail in determining the nature of the Regime and its influences from the historical time. Only after this process, one can move on diagnoses that will allow understanding the complex change of paradigm in the political realities that affect the Francoism.
\end{abstract}

KEY WORDS: Francoism; political theology; Catholicism; C. Schmitt; legitimacy.

Cómo CITAR ESTE ARTículo / CitATION: Cómo CITAR eSte ARTículo / Citation: Sales, Juan Carlos. 2021. «La cuestión teológicopolítica en la legitimación del franquismo. Premisas conceptuales y evolución histórica». Hispania Sacra LXXIII, 148: 575-583. https://doi.org/10.3989/hs.2021.044

Recibido/Received 20-03-2020

Aceptado/Accepted 13-10-2020

\section{INTRODUCCIÓN}

Una exégesis del Quijote sugiere que la locura del caballero español se debe a la pérdida de un mundo teológica-

Este artículo se enmarca dentro del programa de Formación del Profesorado Universitario, con referencia FPU16/04193, desarrollado en el grupo de investigación Historia Social Comparada de la Universitat Jaume I. $271 X$ mente ordenado bajo el catolicismo. El nuevo mundo que lo reemplaza, surgido a lo largo del siglo XVI, es un mundo al cual el caballero ya no se siente pertenecer. Este caballero, que es católico de forma absoluta, mantiene sin embargo su fe y, de alguna manera, pretende restablecer por él mismo un orden cósmico ante Dios, la Iglesia y el Imperio que juntos fundaron. Es aquí cuando la fantasía del héroe comienza (Villacañas 2017). La fantasía aparece cuando la acción heroica se compromete con una actitud completa- 
mente fideísta, hasta el punto de negar las circunstancias con la que la realidad lo oprime. Y si en su ensueño persiste la actitud imperial es porque esta sirve para establecer la ordenación de Dios a través de la continua catolización de todo lo demás. La fantasía del Quijote se corresponde con la imposibilidad de comprender las nuevas formas que rigen el mundo, las cuales es incapaz de aceptar pero de las que no puede escapar sino haciendo uso del dispositivo de la locura. La lucha es entre una razón todavía medieval y un mundo ya moderno. En el fondo, esta es la lucha de siempre del tradicionalismo ideológico.

Que este intento de reconquista de lo imperial, en el sentido católico tradicionalista, no se abandone en España hasta el fin del franquismo solo se comprende por las características históricas de la conciencia tradicional española. Movimientos persistentes como el carlismo o el integrismo católico dan fe de ello. El imaginario católico imperial es poderoso y está presente en los escritos españoles contemporáneos: en Nocedal y en Pemartín, en Siglo Futuro y en Acción Española. Su núcleo existencial radica en volver a unir aquello que el proceso de la Modernidad distribuyó en esferas de acción diferenciadas, una vez desligadas de la potestad religiosa y determinadas en estamentos autónomos: el Estado -típicamente hobbesiano-, la conciencia individualizada, la libertad cultural y religiosa, etcétera. Esta separación de esferas es propia de una secularizada modernidad representada a la manera weberiana, ${ }^{2}$ mientras que el gran esquema del Quijote es su entregada reunión bajo la égida del Dios católico y su ordenación bajo una teología fundamental.

Como se puede suponer, una ordenación política dirigida por la jerarquía ontológica de la teología no es algo novedoso. Ciertamente, las primeras grandes civilizaciones se sustentaron en una idea de religión que se proyectaba directamente en el modo de organizar la sociedad, como la antigua teocracia hebrea, si bien cada una de estas civilizaciones respetaba una forma específica de hacerlo. Posteriormente, las sociedades medievales europeas fueron capaces de mantener una concepción ampliamente teocéntrica en su forma de entender la realidad y la construcción social derivada de ella. Sin embargo, tras el paso a la Modernidad, quienes defendieron conservar este planteamiento totalizador mediante la cosmovisión teológica quedaron en el espectro - típicamente moderno, por lo demás- de la «derecha política».

Siguiendo esta línea, en este análisis se van a utilizar cuatro campos conceptuales como base que interrelacionan el espacio político y el espacio religioso atendiendo a sus diferentes grados de influencia e importancia. Los primeros dos conceptos se establecen en la dialéctica religión/política desde un prisma muy sencillo: la religión aspira a influir en la política o, directamente, a ordenar las estructuras de la misma, y siempre de forma consciente. Dependiendo del grado de transigencia se podrá hablar de «catolicismo político» o de "teología política» en un sentido tradicionalista. Este sentido concreto se contrapone a la denominación de «teología política» secularizada, donde no se aplican conscientemente las categorías religiosas a las políticas. Este

Sobre el estatuto de la modernidad como estadio histórico y su relación con el elemento religioso, me remito aquí principalmente a Weber 1997, Schmitt 2009, Blumenberg 2008. concepto, así como el de "religión política» que también se analizará, se diferencia de los anteriores debido a que presuponen una necesaria secularización de la naturaleza religiosa, al menos en la forma clásica de unión con la política.

\section{LA TEOLOGÍA POLÍTICA TRADICIONALISTA}

En los cánones de la corriente tradicionalista decimonónica española la fuerza de la intransigencia ideológica típica de la extrema derecha advierte, a la manera donosiana, que permitir el acercamiento a posturas tolerantes con la modernidad y más o menos democratizantes solo tiene como camino marcado el descenso al socialismo y al anarquismo. Juan Donoso Cortés es aquí una fuente verdaderamente inagotable de ideología tradicionalista y teológico-política, y su juego de oposiciones teóricas dibuja en la política intransigente su rasgo más marcado. Así, hay un gran tema en la doctrina teológica del Donoso maduro, librado ya completamente de su pasado liberal-moderado, que se constituye en la radical separación entre verdad y error. Es radical precisamente porque la razón teológica permite que este proceso de diferenciación resulte evidente y claro. ${ }^{3}$ Esta separación es a todo punto esencialista, ya que una parte conduce sin remedio al abismo, al pecado y a la flaqueza moral, mientras que la otra representa la gracia, el amor, lo bueno y, en último término, la virtud misma de Dios. El dualismo teórico es insalvable para Donoso. En el engranaje de la dualidad dispone las piezas de toda su resultante argumentación, y en ella quedan ensartados el resto de los temas en torno al integrismo. La clave de todo esto es que la fe, y no la razón humana, es la única que proveería de legitimación en el terreno político (Donoso 1854).

Esta vuelta del poder teológico al campo de la política, entendido como el fenómeno ideológico que intenta sistematizar el hecho religioso como legitimador de la praxis política, queda usualmente referida mediante el término "teología política», aunque parece más conveniente, para el desarrollo de este trabajo, aplicarle el epíteto de tradicionalismo teológico-político (González Cuevas 2000, 20). ${ }^{4}$ Esta sistematización de ideas procedentes del ámbito teológico se refleja, con la adecuada mediación, en la dirección de las opciones políticas. Tal mediación es necesaria siempre que se tenga en cuenta que el contexto histórico es progresivamente hostil a estas concepciones y ya no se forman como algo "natural»; una naturalidad que sí se daba en tiempos premodernos donde el paso de lo religioso a lo mundano procedía por los cauces de una incuestionable tradición. En efecto, la presencia de teología política que se diagnostica ahora es la que se ensarta en pleno siglo XIX, y que nace como una lucha del conservadurismo ante los espadazos de la razón ilustrada y sus derivaciones.

Llegado este punto se puede argumentar que la «derecha», entendida como un campo ideológico amplio, no tie-

3 Los hechos de 1848 dieron al traste con el programa de equilibrios liberal-moderado en el que anduvo Donoso hasta entonces. Por eso se le ha llegado a considerar como un producto del terror del 48. Ver Schmitt 2001, 228. A partir de 1848 configura su Katechon ya en un sentido propiamente cristiano, como contención del Anticristo, siendo este el comienzo real, y no tanto metafórico, de la oposición al lado ruin de la humanidad.

4 Para una profundización del autor en este tema: González 2001. 
ne por qué confrontarse de facto a aquello que ya desde finales del siglo XVIII representó la revolución de la burguesía. Así, un gran espectro de quienes apoyaron la entrada en la modernidad no abandonaron sus posiciones moderadas; tampoco representó esto una actitud antirreligiosa, aunque se extendieron otras vías de entender lo religioso. Es por ello que suele hablarse de "extrema derecha» cuando se habla de la teología política que efectivamente combate el discurso ilustrado in toto, controlando la política y todas las demás esferas sociales mediante la teología. Dentro de este extremismo se encuentran también las derechas radicales más "revolucionarias». ${ }^{5}$ Sin embargo, la derecha revolucionaria - salvado el momento de contradictio in terminisaboga por sintetizar a su manera una serie de elementos que ya presuponen la mentalidad plenamente moderna, como son las doctrinas socialistas o nacionalistas. En este sentido, no solo se debe indicar que la tradición denominada como "revolucionaria» se representa en movimientos como el fascismo, sino que sus presupuestos chocan con la esencialidad de la teología política antes descrita.

\section{RELIGIÓN Y POLÍTICA EN EL CATOLICISMO SOCIAL ESPAÑOL}

Desde luego que el catolicismo en España, y la fundamentación teológica de una sociedad civil y política, no fue un campo exclusivo del integrismo de las derechas radicales. Especialmente a partir de los años sesenta del siglo XX se reivindica un tipo de teología política muy distante ideológicamente de la establecida por el conservadurismo autoritario, cuyas raíces históricas se deben buscar en aquellos grupos católicos que desde finales del siglo XIX intentaron adaptar las exigencias teológicas a la modernidad liberal. Esta corriente católica que pretendía cierta unión de religión y política desde una perspectiva más tolerante hacia la modernidad se corresponde usualmente con la corriente del catolicismo social (Callahan 2002, Laboa 1994, Suárez 2014). Por lo demás, cabe afirmar desde el principio que el liberalismo español no se acercó a posturas antirreligiosas, sino que este se entendía como abiertamente católico y fue proclive a entremezclar liberalismo y catolicismo como ya estaba ocurriendo en otras partes de Europa en consonancia con el modernismo, siguiendo así el espectro propio que habían abierto los ilustrados en Europa, entre ellos los españoles.

Es necesario ofrecer una distinción clara, por tanto, entre las dos consignas en pugna dentro del terreno católico español que, como se entiende hasta ahora, quedan defi-

Hay, por supuesto, otras corrientes que persiguen la total unión entre la cruz y el báculo, como por ejemplo el carlismo. Ciertamente, el carlismo entra en la concepción ideal de la teología aplicada a la política tradicional, sobre todo si atendemos a que su ideario fundacional se cifra en el conocido lema "Dios, Patria y Rey», donde la religión justifica tanto la fuerza de la tradición como el poder monárquico absolutista, y asimismo determina los ordenamientos social y político. Por descontado, el carlismo también reivindica el papel del soberano absoluto por la gracia de Dios y no por la soberanía nacional, una idea típica del tradicionalismo antes descrito, ciertamente alérgico al empoderamiento político de las masas. Aunque con modulaciones propias de la evolución histórica, como la disidencia integrista de 1888 o el posterior cisma mellista, el carlismo como grupo ideológico se mantendrá inamovible en su proyecto antiliberal y tradicionalista hasta el franquismo. Ver Aróstegui 2003. nidas en cuanto a la recepción o rechazo de las premisas de la modernidad burguesa. Utilizando las categorías de Jean-Marie Donégani, es interesante aquí señalar que el catolicismo radical antiliberal se sostiene tanto por su «integralismo» como por su «intransigentismo». "Integralismo» designa la aspiración de este grupo a someter bajo dirección de la religión, utilizando el edificio teológico, todos los aspectos de la vida de las sociedades y de la existencia de los individuos. "Intransigentismo», por el otro lado, describe la actitud de rechazo total del pensamiento religioso a los principios y valores que fundamentan el mundo moderno, por el cual no se acepta en ningún caso las veleidades de la modernidad, y por ello tampoco el liberalismo, que puede ser así condenado como herejía y pecado extranjerizante (Fouilloux 1995, 84-85).

Por el contrario, el modelo católico más cercano al ideario liberal, el llamado catolicismo social, propulsó sus ideas por Europa de forma notoria a partir de las encíclicas del papa León XIII. Elegido cabeza de la Iglesia católica en 1878, entre sus textos - polémicos en la época teniendo en cuenta el conservadurismo de la curia romana- es especialmente relevante la encíclica "Inmortale Dei», donde se conmina a los creyentes a participar activamente en la vida política del Estado moderno. A partir de ahí se avezó el movimiento por la "transigencia» entre las nuevas ideas de la modernidad y el culto católico en Europa, cuyo hito remarcable fue el influyente congreso de Malinas de 1863.

La repercusión en España fue notable y, si bien este catolicismo no consiguió afincarse en parcelas de influencia política real, sí tuvo una influencia considerable en cuestiones sociales, lo que a la larga se restituiría en agrupaciones políticas estables y participativas. Por entonces, la organización más importante del catolicismo social español en el reciente siglo $\mathrm{XX}$, y que entró de lleno en la arena política laica, fue Acción Católica. Según Callahan, esta agrupación político-religiosa

señaló el principio de un populismo ultramontano que trascendía las divisiones históricas del catolicismo español a favor de un movimiento basado en la defensa de los intereses de la Iglesia y un programa conservador que con el tiempo constituirá el fundamento ideológico de una nueva derecha católica decidida a promover una organización radical de masas (Callahan 2002, 108-112). 6

Del mismo modo, la aparición de los círculos católicos y sindicatos de corte cristiano se fueron multiplicando en las mismas décadas de principios de siglo, sentando así las bases ideológicas de futuros partidos y asociaciones cristianas participantes - bien activamente, bien como posibilistasen los procesos políticos españoles.

Tras todo esto, queda patente que el catolicismo social aspira a influir religiosamente en los campos de acción de la política y de lo público en general, pero siempre respetando su autonomía como campos diferenciados; diferenciación que está en la base del surgimiento de la modernidad. La

En torno a los círculos obreros en España cabe mencionar el especialmente fecundo trabajo del jesuita castellonense Antonio Vicent, cuya entrega al carácter social de la Iglesia, unido a las aportaciones materiales del Marqués de Comillas, le llevaron a convertirse en unos de los más insignes promotores del catolicismo social. 
progresiva cristianización de una sociedad cada vez más compleja y tecnificada, amenazada por el implacable ateísmo, y cuyos problemas sociales emergen desde la explotación capitalista del proletario común, edificarán el significado de esta concreta teología política.

En España, la doctrina político-religiosa proveniente del catolicismo social quedará representada por los escritos del jesuita Alfonso Álvarez Bolado (1928-2013), de especial relevancia en el panorama político español durante el periodo de la Transición. Bolado trabaja codo a codo con las tesis de los teólogos alemanes Johann Baptist Metz y Jürgen Moltmann, y la crítica a una despiadada teología política del nacionalcatolicismo franquista vertebra su teoría. El jesuita español entiende que lo que ha ocurrido en el seno de la Iglesia durante el franquismo es la dominación del autoritarismo político, que ha utilizado el poder espiritual para el fin franquista de la eliminación del adversario. En este sentido, lo que critica con más vehemencia es la pasividad de los grupos religiosos que han hecho suyas reivindicaciones - «cruentas» y «deleznables»- de la extrema derecha franquista, legitimando así esa opción política autoritaria y renunciando a su verdadero propósito, eminentemente liberador y pacifista (Álvarez 1999, 60). Conseguir este propósito pasa necesariamente por reactivar la conciencia crítica en la que toda Iglesia pastoral debe sustentarse, para así fungir de guía espiritual ante los nuevos retos globales.

Como resulta evidente, desde esta perspectiva se supone explícitamente la separación entre el terreno eclesiástico y el estrictamente mundano, y de esta manera cabe la crítica de la dominación religiosa de otras esferas pretendidamente autónomas: «la fórmula intentada [de una teología política nacionalcatolicista], que se ha tratado de ensayar hasta el término del Vaticano II, es la reinstauración del régimen de cristiandad, es decir, la reconstrucción de la totalidad de un sistema social, desde sus niveles culturales hasta socioeconómicos» (ibídem, 274). ${ }^{7}$ Esta opción impugna la demanda contrarrevolucionaria e intolerante del nacionalcatolicismo, y aboga a su vez por una teología política de fines cristianizantes pero respetando las premisas de tolerancia política liberal, ya excluido el integrismo tradicionalista. En su lugar, la opción de la nueva teología política caminará por la senda de la transformación gradual de la sociedad con vistas a la mejora de las condiciones materiales de las clases bajas, utilizando los medios de la acción social en la línea del humanismo cristiano. Sus resonancias al sentido lato de la popular teología de la liberación y a las nuevas teorías marxistas son claras. ${ }^{8}$ Esta especie de fideísmo de la praxis política y social tiende a enarbolar el mensaje del evangelio para alumbrar unas luchas sociales ya muy secularizadas en la época. En resumen, la teología política del catolicismo social requiere una conciencia crítica en las relaciones entre Iglesia y Estado para así penetrar en la conciencia social mediante el mensaje evangélico, recristianizando la sociedad civil y participando activamente y con plena intención en el escenario político: «Por su mismo carácter teológico-funda-

\footnotetext{
Para una lectura de este tema desde la historia cultural, ve Muñoz 2006.

8 «La tesis capital de la teología política, que el amor cristiano solo es objetivo y creíble cuando se acredita en la transformación humanizante y liberadora de las estructuras naturales y sociales, se resume aquí con ingenua sencillez» (ibídem, 215).
}

mental, la teología política supone un movimiento autocrítico de la praxis eclesial; busca la institucionalización de una conciencia crítica permanente respecto a la ubicación de la Iglesia en la sociedad y en su trama de intereses» (ibídem, 291). ${ }^{9}$

Se podría decir en breve que tanto la teología política típica del integrismo, ejemplarizada con el nacionalcatolicismo, como en la del catolicismo social, impulsado especialmente tras el concilio Vaticano II, son dos modos de ver la religión como un elemento activo en la esfera política. La separación esencial entre ambos consiste en que en el catolicismo social la religión no es nunca más un elemento legitimador de la propia acción social, esto es, no estructura ni da sentido a un campo como la política, pues la misma política es autónoma ante todo lo demás y el catolicismo respeta tal independencia. Si fuera de otra manera, la deseada adaptación del cristianismo a los nuevos moldes modernos, cuyo embrión es el gesto tolerante de León XIII, no podría llevarse a cabo, y por tanto este modo de hacer religión en la vida pública quedaría arrasado tras el paso decidido de los católicos menos tolerantes. Debido a ello, como es lógico, el catolicismo social será objeto de ataques furibundos por parte del integrismo. Como se había aprendido de Donoso, no se puede coquetear con el error sin caer de pleno en él. La crítica intransigente se dirigirá por mor de la pobre posición en la que el catolicismo ha quedado: ya solo como un actor más del proceso de ordenación social, y ni siquiera el más importante. De esta forma, lo religioso ya no resultaría propiamente legitimador en la moderna realidad social ni en su política.

\section{TeOLOGÍA POLÍTICA MODERNA. LA POLÍTICA COMO SECULARIZACIÓN DE LA TEOLOGÍA}

¿De dónde proviene que lo religioso ya no resulta legitimador en la realidad política y social? Si echamos la vista atrás, la teología política tradicionalista se basaba en el factor de legitimación, en el sentido weberiano de dominación tradicional, que la religión tenía en el aspecto político, una relación entre política y religión que había sido normalizada en el transcurrir de los siglos. Es necesario ahora preguntarse si tras cien años de luchas a muerte con los delfines del ateísmo, con secularizaciones y con galicanismos, se puede establecer que el siglo XX no ha desechado este tipo de fuerza religiosa que aspira a ordenar la realidad social. En otras palabras: ¿en qué medida y bajo qué presupuestos se ha mantenido la religión como un factor tan determinante en la política del siglo XX como para permanecer como elemento «legitimador»?

Para responder a esta pregunta es necesario ampliar el espectro de referencia acerca de lo que la teología política puede significar. En el sentido estrictamente schmittiano, el término teología política «nada tiene que ver con la exis-

9 Para Bolado, esta teoría es similar a la «teología política eclesiocrática decimonónica» y, sin embargo, ahora es crítica: busca romper con el sectarismo y colabora en el proceso de la libertad moderna/ ilustrada. Esto es opuesto a lo que él denomina como teología política nacionalcatolicista que, siendo de algún modo eclesiocrática también, es antimoderna y de reconquista. La derivación práctica de su teología política crítica será, de hecho, la corriente de la teología de la liberación. 
tencia de formas políticas históricas que hayan apelado al catolicismo como fuente de legitimidad, ni con el hecho, frecuente, de que los poderes institucionales católicos hayan asumido funciones de gobierno temporal» (Villacañas 2016, 9 y ss.). En la teoría de Schmitt desaparecen las formas sobre las que se ha hecho explícito el modo de entender la teología política tradicional, es decir, que las explicaciones en las que el elemento religioso explícito se utilizaba como legitimador de las acciones políticas concretas quedan anuladas. No importa cuánta intransigencia se defienda ni el grado de compatibilidad con la modernidad, pues ninguna de estas características fundamenta la verdadera legitimación de lo político desde lo religioso.

Para Schmitt hay una afinidad estructural entre los conceptos teológicos y los políticos. Descubrir y determinar estas afinidades es la base de todo su trabajo sobre la soberanía y, a través de este, del decisionismo. La legitimación de la política reside finalmente en el concepto jurídico de soberanía (Schmitt 2009, 117). Schmitt, siguiendo en esto a Max Weber, entiende que el proceso de la modernidad ha escindido y diferenciado las esferas de sentido que antes se aunaban bajo el peso de la religión. Pero esto no es un obstáculo para que la teología política sea una realidad en la política contemporánea, sino que, más bien al contrario, «la teología política solo juega con plena conciencia de sus profundos supuestos dentro de esta teoría de la separación de las esferas de acción», pues a decir de Villacañas (2000, 26 y ss.), «lo específico de la teología política reside en que supone la autonomía de la política como terreno de conflicto y de tensión». La teología política en el sentido schmittiano, por tanto, solo es posible en el mundo moderno, donde la política ha quedado separada de la religión y ha encontrado una posición autónoma respecto a esta. Y sin embargo, es irremediable la búsqueda de «afinidades» entre la política y la teología, ya que los supuestos de la primera descienden de categorías secularizadas de la segunda. Es por ello que todas las teologías políticas específicas antes expuestas, y que orbitan fuera de la concepción schmittiana, tienen un sentido esencialmente diferente a este y su legitimación queda reducida a mera referencia a un Estado metafísico que de alguna manera ha de volver a regir, de forma ilusoria, el mundo moderno.

Aquí, por tanto, el uso del término "teología política» va a referenciar el sentido schmittiano de diagnóstico y explicación de la moderna teoría política; es decir, que supone un modo de examinar los conceptos políticos desde la óptica de la ciencia política. Por supuesto, queda esto muy lejos de las anteriores formulaciones entendidas dentro del tradicionalismo ideológico-político, en donde se «fuerza» a la religión católica a servir de legitimación a un orden político concreto, método que utilizará luego el franquismo. La escisión conceptual por mor de la precisión teórica es fundamental e inevitable.

Una vez entrados en este camino se aprecia como sintomático y equivocado el que Álvarez Bolado incluya a Schmitt en el grupo de aquellos integristas que defienden una unión esencial entre las políticas llevadas a cabo en una sociedad y la religión, acusando al alemán de que, mediante su teología política, pretende reducir lo cristiano a «religión política». Álvarez Bolado $(1975,58)$ recrimina a Schmitt el haber formado parte de esa lacra «teológico-política» que fue el nacionalcatolicismo, por el cual la Iglesia cristiana perdió su horizonte humanista y, hasta cierto punto, progresista. Como ha sido expuesto hasta ahora, el catolicismo social se entreteje con la vertiente ilustrada del iusnaturalismo racionalista que, siendo ideológicamente afín a la democracia liberal, entrega su legitimidad política al puro voluntarismo jurídico bajo la dirección de las mayorías y la «abstracta» voluntad general; decisión de la masa que en último término no solo afecta a los asuntos humanos, sino a los divinos. Por su parte, el integrismo católico desprecia esa connivencia con el liberalismo proveniente de la ilustración, pues hace al Dios impotente, que existe pero no interviene soberanamente en los asuntos mundanos, un Dios propio de la burguesía liberal y su deísmo. En cambio, el Dios del teísmo se conforma como un ente omniabarcante e interventor, y por tanto también soberano político, cuya defensa se postulará radicalmente desde el integrismo de extrema derecha, por ejemplo desde Acción Española (González 1998, 340, 350). En ambos casos, la utilización de una concepción teológica es circunstancial a la doctrina política en cuestión, sea esta liberal o autoritaria. El tipo de Dios y su influencia determinan qué clase de actividad político-social se da y cómo se desarrollan estas disposiciones.

Volvamos a Donoso por un momento. Uno de los movimientos más agudos del político español, a propósito de una crítica a Proudhon, fue aplicar la lógica totalizadora del teísmo al espectro social, reconociendo que en toda cuestión política se halla irremediablemente una cuestión teológica. Esta especie de panteísmo político le sirve para desarrollar el resto de su doctrina. La acusación hacia quienes se piensan fuera de la teología es realmente eficaz, y así como un marxista puede elaborar su teoría negando la forma teológico-burguesa de hacer política, del mismo modo no puede desligarse de la referencia constante de su contrario, aquello que le hace rebelarse y que explícitamente quiere desarbolar. En el siglo posterior, Carl Schmitt se hizo también con la premisa de que, por mucho que se reniegue de la teología, en asuntos de ciencia social no se la puede esquivar, poniendo a la vez en cuestión a los más reputados teóricos de su época, como fueron Hänel, Preuss, Gierke y, por supuesto, Kelsen (Schmitt 2009, 39-40, 58). ${ }^{10}$ Por ello es esta una argumentación hábil con la que forzar al adversario a unirse a su batalla. Para Heinrich Meier

Schmitt no usa el término "teología política» sólo para teorías políticas que, como la suya, declaran estar ancladas en la teología. Más bien sabe cómo detectar 'teologías políticas' incluso donde toda teología es expresamente repudiada, donde la política es negada y donde se declara que toda teología política ha sido «liquidada» (Meier 2008, 92). ${ }^{11}$

Esto quiere decir, en un primer momento, que toda política contemporánea tiene una conexión más o menos velada con las categorías de la antigua teología; pero más importante aún es comprender que esta afirmación declara tajantemente como imposturas aquellas corrientes políticas

10 Y lo mismo que Donoso veía en Proudhon un anarquista incapaz de librarse de la teología, Bakunin es para Schmitt un teólogo de la antiteología.

11 Para la gestación del tema en este autor, consultar Meier 2003. 
que, justificándose en una presunta legitimidad implacable, se autodenominan como la genuina «teología política».

Claro queda que el fondo de la teoría schmittiana es deudora de Donoso en cuanto que su teología política representa una crítica al normativismo liberal y el Estado de derecho resultante. La teología política schmittiana tiene que ver más con este sentido, es decir, con la imposibilidad de un política normativa y abstracta que no dependa de la decisión soberana extraparlamentaria, que con cualquier otra cosa (Schmitt, 2009). ${ }^{12}$ La exposición binomial donosiana mantiene una línea directa con la animadversión hacia el parlamentarismo, el democratismo y las instituciones liberales, cuya razón es sencilla de ver para él: las empresas de la patria no pueden dejarse en manos de políticos que pretendan guiarlas escudándose en la impertérrita autonomía de la razón. ¿Cómo podría ser que el imperfecto intelecto del hombre sirviera para elegir el camino perfecto, el que evita la desolación marxista? Pues si no se está en el camino de Dios, el hombre se pierde en la «libertad» de elegir al Anticristo. Pretender salvar la nación mientras se tantea permanentemente el error: esa es su animadversión hacia la "clase discutidora», clase que, perteneciendo al liberalismo burgués, elude la decisión. La facultad de escoger es el peligro de la libertad, pues puede abocar a elegir el error (Donoso 1854, 39, 90).

\section{RELIGIONES POLÍTICAS, O LA SACRALIZACIÓN DE LA POLÍTICA MODERNA}

En cuanto a la unión entre religión y política con propósitos legitimadores, ciertamente autoritarios, que para el caso del nacionalcatolicismo Bolado había descrito como "religión política», debe primero aclararse la naturaleza simbiótica de ambos factores unidos en un sistema ideológico concreto. Es un hecho claro que el franquismo, nacido al albur ideológico de las "extremas derechas», hizo suyo el registro retórico tradicional-católico, presentando así como cruzados a los combatientes, como mártires a los caídos, como santos a los participativos, como enviado por la gracia de Dios al caudillo y como ofrenda divina la causa militar. Promover la idea de que el naciente Estado traía consigo el apoyo y la fundamentación necesaria por parte de instancias poderosas y eternas, cuyos discursos quedaban anclados además en el imaginario del pueblo español, era el modo de presentarse bajo la pátina de la legitimación una vez conseguida la victoria. Y desde luego que esta inicial legitimación, con todos los procedimientos habidos posteriormente, encuentran en la definición de religión política un concepto explicativo bastante ajustado; con todo, debe diferenciarse de lo que para los expertos en movimientos fascistas representó este sintagma.

12 En cierta manera, hay también una impostura en Schmitt cuando toma por buena la frase donosiana de que "todo es teología política». Se puede decir que el Donoso maduro se apropia del Libro sagrado y lo convierte en manual de ciencia política bajo algunos de sus dogmas fundamentales. Pero como se ha explicado, la estructura de la teología política como reflejo de categorías teológicas en la política moderna conlleva un funcionamiento esencialmente distinto. Para más reflexiones sobre el acercamiento de Schmitt al derecho natural y su conflicto con la teoría moderna del estado, ver D’Ors 1996.
El término religión política estuvo marcado desde sus inicios como un modo identificativo de la naturaleza de los totalitarismos del siglo XX, especialmente del fascismo surgido tras la Primera Guerra Mundial. Su carácter totalitario y caudillista-providencialista fue el resultado de la estetización de la política de masas que además favoreció, en mayor o menor medida, la emergencia de un líder sacralizado. ${ }^{13}$ Los fascismos primigenios en Italia y Alemania estuvieron transidos por este manto sagrado y, sin embargo, en esos espacios políticos quedaba ya implícito la esencia secularizada de la religión: la Iglesia se integraba en el Estado, pasando este a detentar las funciones pastorales; ${ }^{14}$ la religión era el nacionalismo radical mismo. Esto es contrario a lo que ocurre en España, donde las prebendas de la institución eclesiástica son casi ilimitadas, y el carácter sacro de la política franquista lo otorga la misma Iglesia católica, y su significación es que la Iglesia tradicional sacraliza el Régimen por sus propios ritos históricos ligados al catolicismo. Lo político no tiene la intención de sobreponerse, en este aspecto, a lo religioso.

Así pues, y en contraposición a la norma fascista mussoliniana, el interés del franquismo en la religión no se reduce solo a la esfera política, sino que existe una vinculación teológica que gracias a su importancia en las tareas de identificación con la causa del 18 de julio consigue estar presente en la política del sistema. Si bien para la Italia fascista el catolicismo fue privilegiado, su presencia fue meramente pragmática, pues la superioridad del poder político sobre cualquier otro - incluido el teológico - era evidente y notorio (Gentile 1990, 230). ${ }^{15}$ En este sentido, la denominación que Antonio Elorza utiliza para denominar al franquismo como proyecto de religión política se debe entender no desde este foco específicamente fascista, sino como la sacralización continua de un régimen político pero que no se impone al espectro teológico, sino que se complementan (Elorza 2004). ${ }^{16}$

El franquismo estuvo imbricado con la concepción de religión política desde el principio aunque, como vemos, de una forma diferente al clásico fascismo, pues la esencia católica tradicional constituía una parte central de su naturaleza fuera de cualquier chispazo revolucionario y lejos de la totalización política. Todo y que los grupos estrictamente católicos y los tradicionalistas asociados al carlismo anduvieran cerca del nuevo poder franquista, y aunque los fascistas españoles nunca renunciaran a la esencia católica de la per-

13 De la ingente bibliografía acerca de la esencia fascista, baste por ahora rescatar: Paxton 2005; Griffin 1993; Payne 1986. Sobre la específica relación entre la vertiente mítico-religiosa y la política, ver Gentile 2001.

14 «En este sentido, la mayor objeción que Griffin había mostrado en un principio ante la idea de la religión política - su incapacidad para subrayar el carácter eminentemente secular de la ideología fascista- quedaba invalidada al insistir Gentile en la novedad que ésta suponía con respecto a otras formas históricas de relación entre lo político y lo religioso: el hecho de que el fenómeno de la sacralización de la política sólo podía producirse en sociedades secularizadas y, por tanto, modernas, en las que se presuponía la laicización del Estado y su autonomía institucional» (Box 2006, 215).

15 Obviamente, el establecimiento de una estética y de una moral divinizada mediante el nacionalismo fascista evocaba la pretensión del nacimiento de una nueva religión ya apartada de la fe clásica.

16 Acerca de la relación entre el franquismo y sus atribuciones ideológico-religiosas, ver Di Febo 2002; Box 2010. 
fecta españolidad, no hubo un intento de legitimación estrictamente teológica del franquismo. Y esto no porque los falangistas - en quienes recayó en mayor medida la responsabilidad de diseñar el franquismo institucionalmente- no fuera fervientes católicos, sino porque su idea de Estado se desligaba tajantemente del contenido tradicionalista y, por tanto, de la asunción teológica de la nación. No hay, pues, un intento de legitimación de totalización católica, aunque se utilice la religión en gran medida para justificar el inicial proyecto nacionalsindicalista del franquismo.

De este modo puede comprenderse que ni Francisco Javier Conde ni de Luis Legaz Lacambra - dos de los teóricos más importantes del nuevo Estado franquista - conceden a la religión más peso que el de influjo simbólico y el control de algunos ámbitos, como la educación y el terreno de la espiritualidad y las costumbres, quedando en todo caso incluida en el proyecto moderno del Estado con reflejos fascistas. De este modo, el caudillo, aunque encumbrado mediante la gracia de Dios, no deja de asomarse a un personalismo carismático igualado al mito del jefe fascista (Conde 1952, Moradiellos 2016). Para Legaz Lacambra (López 1996, 216223) si bien gran parte de la esencia del Régimen nacionalsindicalista se establece mediante la espiritualidad cristiana de la religión, esta no puede justificar, en modo alguno, su armazón teórico-político. La argumentación sigue adelante en este punto cuando defiende, alineado con el ideario de Balmes, que el papel salvador del cristianismo debe proceder de hecho desde el Estado, un Estado nuevo que se mira en el espejo de las formaciones fascistas irremediablemente modernas.

\section{LA LEGITIMACIÓN RELIGIOSA DEL FRANQUISMO}

Una vez seguido este hilo podemos decir que la justificación religiosa del Régimen, en términos de legitimidad política, es huera de acuerdo a las estipulaciones de la teoría schmittiana. El franquismo se ha visto "autolegitimado» por la esfera religiosa y su infalibilidad, pero realmente esto solo sucede como impostura, la misma impostura que ya se había detectado en la acepción por parte de Schmitt de considerar a Donoso un teólogo político con connotaciones modernas. En realidad, como había apuntado el jesuita Álvarez Bolado, la Iglesia dominada por la facción integrista había prestado sus ropajes al franquismo, pero esto no podía significar más que una mera apariencia de legitimación, pues en el mundo moderno de dominación puramente política no podía regir una institución autocomprendida todavía como ultramundana. Solo la política, una vez secularizada la teología, era la vía teórica para entender la verdadera soberanía; y sin embargo, tampoco el Régimen trascendió nunca hacia la fórmula de conformación de un Estado fascista total. El franquismo y su base integrista podían verse entonces como dictadura nacionalcatólica, pero en ningún caso como legitimidad teológico-política. ${ }^{17}$

17 «Los filósofos políticos contrarrevolucionarios deben precisamente su significación actual a su resolución para decidirse. Tanto exaltan el principio de la decisión, que a la postre aniquila la idea de legitimidad que fuera su punto de partida. Cuando Donoso Cortés vio que la monarquía tocaba a su fin, porque ni reyes había ya, ni nadie con valor para serlo sin contar con la voluntad del pueblo, sacó la consecuencia última de su decisionismo, es decir, reclamó la dictadura política. La
La pretensión de la legitimación política moderna a través de las categorías del tradicionalismo católico, que de alguna manera tiende a revertir o minimizar el efecto que la modernidad liberal consiguió en suelo español es, de acuerdo al diagnóstico schmittiano, una quimera. Las formas en las que este integrismo pretende reunificar las esferas de acción modernas, y con ello devolver el terreno político a la autoridad de la religión, no es simplemente un ejercicio teóricamente improbable, sino que no puede pretender servirse de la majestuosa legitimidad con la que se presenta en un mundo que es irremediablemente moderno.

Por la misma lógica es erróneo achacar a Schmitt el pertenecer a la corriente del tradicionalismo político-teológico. Ciertamente, el jurista alemán idealiza el pasado en cuanto a no dominado por unas fuerzas técnicas extremas y extensivas, y en ese sentido hay en él cierta sensación de romanticismo por el recuerdo de épocas anteriores. Pero esto choca de pleno con su políticamente avanzada forma de entender el autoritarismo como legitimidad, más cerca sin duda del conservadurismo autoritario de corte fascista que no del tradicionalismo integrista. Esta predilección se tradujo, más tarde, en el apoyo hacia el programa nacionalsocialista y, especialmente, a la figura del Führer; apoyo que podría recibirse con no pocas reticencias por parte del sector clerical más tradicionalista. ${ }^{18}$

De la misma forma es imposible que Schmitt fuera uno de los primeros receptores de la «tecnocracia», como sugiere Zaratiegui $(2016,56)$. Su doctrina de la soberanía política influye en la conocida etapa tecnocrática franquista, pero es completamente contraria a la tecnificación de esta, pues Schmitt vincula tal proceso a la burocratización misma de la vida política (a cargo de un soberano qui administre et ne gouverne pas). Se podría aceptar que Schmitt propendiera a «encarnarse en los regímenes de fuerza», y sería deseable la matización cuando afirma que pertenece a «la tradición ordenacista y de intervención estatal», pero que se le relacione con "un tipo de burocracia» - por muy bélica o nazi que sea- es erróneo. Con ello se da a entender que la configuración política de Schmitt se desvincula del decisionismo político más lato en favor de las decisiones adoptadas por grupos de expertos y gabinetes de acción administrativa despolitizados. Esto en modo alguno puede ser así. Desde sus primeros escritos hasta la era apoteósica de la tecnocracia, Schmitt se muestra crítico tanto con la técnica industrial, que asocia a la destrucción misma de lo político, como a la dominación burocrática del Estado, que para él significa el triunfo de la inactiva ordenación demócrata-liberal. Por su aversión al Estado de derecho liberal y las posiciones conniventes con él, y no tanto por su afección hacia la tecnificación misma, mantiene Schmitt algún tipo de enlace con el autoritarismo tecnocrático. Por eso, por ejemplo, considera

posición de De Maistre, a que antes aludimos, implica la reducción al puro elemento de la decisión, decisión absoluta, creada de la nada, que no razona, discute ni se justifica. Pero esto es esencialmente dictadura, no legitimidad» (Schmitt 2009, 57).

18 El Führer «toma en serio las advertencias de la historia alemana [descarríos político-sociales achacados al estado de derecho liberal]. Esto le da el derecho y la fuerza necesarios para fundar un nuevo Estado y un nuevo orden». Todo el pasaje constituye una diatriba explícita contra la política del liberalismo y la división de poderes. Así, Hitler no solo es el gobernante de la nación, sino que es además el «juez supremo del pueblo» (Schmitt 2001, 115). 
el alemán que el humanitarismo tiene en la política un rasgo perverso y de ahí, recordemos, proviene la crítica hacia el catolicismo social. Solo si tomamos su acepción de la soberanía decisionista como forma contraria al principio liberal se puede ser maestro ideológico tanto de epígonos franquistas cercanos a la falange como de los tradicionalistas católicos que se inspiran en el clasicismo católico. Solamente este, y no otro, es su núcleo común.

\section{CAMBIO DE PARADIGMA, ¿'NUEVA LEGITIMACIÓN?}

La cuestión crucial aquí es entender que solo mediante la aceptación de esta dudable legitimación religiosa (que lo es meramente en la apariencia tradicionalista) se ha de ver la facilidad con la que el Régimen pudo transitar hacia rumbos alejados de su pretendida concepción reaccionaria. En un periodo de internacional desconexión entre la institución de la Iglesia y los regímenes autoritarios desenvueltos como concepciones de religión política, la imposición de las nuevas virtudes que el panorama en occidente ofrecía en forma de neutralidad ideológica y avance económico-técnico.

Tanto Conde y como Legaz habían diagnosticado este cambio de paradigma político a la altura de los años 50 , producido por el auge de la técnica y los apremios de la economía internacional. Las teorías que habían promulgado anteriormente como fundamentadoras del Estado nacionalsindicalista quedaron desprovistas de todo respaldo internacional tras la caída de los fascismos y el imperioso auge de nuevos modelos políticos. Esta transformación de modelo es identificada claramente como una forma de desideologización (López 1996, 216). En el régimen franquista este tipo de cambio fue obviamente forzado por el contexto y no una derivación interna del propio franquismo, si bien este contaba con la capacidad necesaria - reducida y en ocasiones azarosa ciertamente, pero suficiente- para la adaptación hacia la supervivencia. En un momento epocal de guerra fría, de lucha contra el comunismo, de la presentación del franquismo como resguardo de la moral cristiana y de su preciada localización estratégica, el breve resquicio que el autoritarismo franquista aceptaba para que la tradición social se mantuviera a expensas de algunos avances modernos fue clave. Pero los cambios conllevaban un desprendimiento de los más íntimos rasgos tradicionalistas en clave ideológica. Esto es lo que detecta José Casanova $(1999,144)$ respecto a la progresiva secularización de los tiempos, en un momento en que «la tecnocracia, las ideologías del desarrollo y las que proclamaban el final de la ideología llegaron a sustituir al catolicismo como base para la legitimación ideológica del régimen ${ }^{19}$

Este proceso de desideologización del contexto global está relacionado, según Schmitt, con el tránsito de neutralizaciones que se llevan a cabo de una época a otra. Pero al contrario de lo que se podría pensar, el auge de la neutralización en los debates sobre la civilización occidental no es exclusiva del siglo XX o de la época de la técnica. Cada tiempo ha sufrido una neutralización como respuesta al agotamiento de un determinado modo de pensar la realidad total,

19 Esta lectura se enmarca dentro de su diagnóstico sobre la secularización y adaptación de las religiones en el mundo actual siguiendo su célebre libro Public religions in the modern world (Casanova 1994). bien fuera de forma teológica, cientificista, moralista... Sin embargo, una vez dado el paso de la época economicista, propia del siglo XIX, a la época de la técnica en nuestra contemporaneidad, la neutralización ha quedado estancada en la zanja de una pretendida neutralidad con la que la técnica evita las postreras propagaciones teóricas y desfonda la carga de las fuerzas ideológicas. El último desplazamiento del centro gravitacional espiritual de Europa ha encontrado un terreno que concluye los desplazamientos, porque es un terreno absolutamente neutral. ¿En qué sentido es neutral?:

La evidencia de la extendida fe contemporánea en la técnica reposa únicamente sobre el hecho de que en algún momento se ha podido creer que con la técnica se había hallado un suelo absoluta y definitivamente neutral. Pues en apariencia no hay nada más neutral que la técnica [...] Sin embargo, la neutralidad de la técnica no se parece a la neutralidad de ninguno de los ámbitos anteriores. La técnica es siempre solo instrumento y arma, y porque sirve a cualquiera no es neutral (Schmitt 2016, 122-123)..$^{20}$

Después de esto, ¿cómo designar los conceptos de soberanía o legitimidad política? Para Schmitt no queda otra solución: la política que quiera gobernar el futuro debe apoderarse de la nueva técnica y transmitir a través de ella sus categorías definitivas. La técnica conferirá el poder al futuro soberano. Esa es la esencia de la política tecnocrática, porque en una época idealmente «neutral» la soberanía recae en el sujeto que posee la técnica y es ella quien otorga el poder (Marramao 1998, 69-78). Esto, analizado con detenimiento, lleva a la aniquilación del concepto clásico del soberano como el último bastión decisorio que está por encima de toda decisión meramente normativa; en vez de eso, el soberano portador de la técnica se descubre como un sujeto pasivo que nunca más es autónomo en su decisión porque depende del poder causal de la técnica.

¿Dónde queda para el Régimen, a partir de entonces, la al menos pretendida apariencia de legitimación teológica? La polémica quedaría descrita en si todavía la religión tiene algo que decir en la fundamentación soberana de un régimen, o si bien hay que plegar velas ante lo que había sido todo un intento de justificación católica. Efectivamente, para Gonzalo Fernández de la Mora (1965) la política se ha desplazado de la lucha ideológica a las formas cientificistas de entender el Estado y sus cuestiones sociales. ${ }^{21}$ Del agotamiento de las ideologías no surge otra que las supera, sino que acontece el páramo antiideológico. Pero el tránsito no resulta ser algo tan obvio como un simple traspaso

20 Para más especificaciones del término "neutralidad política» se puede también ahondar en el primer corolario al concepto de lo político, titulado «Resumen de los diversos significados y funciones del concepto de la neutralidad interna del Estado (1931)».

${ }^{21}$ Una buena definición del interés que puede tener aún la religión en la política, siguiendo este hilo, podemos encontrarla en González $(2012,113)$ : «Las tesis de Fernández de la Mora, que fueron muy discutidas, eran reflejo del nuevo contexto social, económico, político y cultural; y suponían, en el fondo, una profunda crítica a los fundamentos de la teología política en que, hasta entonces, había descansado el proyecto político del conjunto de las derechas españolas, y en particular de las fuerzas que apoyaban al régimen nacido de la guerra civil. En el fondo, Fernández de la Mora venía a decir que los viejos planteamientos teológico-políticos eran epistemológicamente incompatibles con los nuevos saberes científicos característicos de la nueva sociedad industrial». 
de valores teológicos eternos a otros igualmente eternos y metafísicos de la ciencia, como una natural transmutación de la fe en la decisión avalada por la infalibilidad teísta en la nueva fe de la eficacia técnica. Desde luego que, en un primer momento, esta se presenta como infalible también, pues por su misma fundamentación científica -además de otras pretensiones metafísicas,- 22 edifica su confianza bajo los parámetros de la prevención del error físico-matemático. Siguiendo este discurso sobre «la época de desideologización», donde a finales del siglo XX la instancia que representa la ciencia se ha colocado por encima de cualquier otro presupuesto legitimador en cuanto a pautas de actuación, esta se convierte automáticamente en la máxima premisa con la que legitimar las orientaciones políticas, pues «en la práctica, lo mismo da no estar sujeto a error que no poder ser acusado de error; lo esencial es que ninguna instancia superior pueda revisar la decisión» (Schmitt 2009, 51).

De todas formas, que en su propia evolución el franquismo quiera sobrevivir mediante la asunción de la técnica y sus resultados económicos es, de facto, la despedida de toda pretensión de legitimidad entendida como tradicionalismo católico. Alrededor de todo esto puede quedar aún, sin embargo, el aliento de la intransigencia que emulaba Donoso, pues la legitimidad que provee la ciencia asegura entrar en el ámbito de lo certero, de lo infalible, si bien esta infalibilidad ya no corresponde al don afilado de la divinidad, sino a la virtud roma de la tecnociencia.

\section{BiBLIOGRAFÍA}

Álvarez Bolado, Alfonso. 1975. "Dios y la ciudad». En Dios y la ciudad: nuevos planteamientos en teología política, ed. Karl Rahner, 27-73. Madrid: Ediciones Cristiandad.

Álvarez Bolado, Alfonso. 1999. Teología política desde España. Del nacionalcatolicismo y otros ensayos. Bilbao: Desclée de Brouwer.

Aróstegui, Julio. 2003. El carlismo y las guerras carlistas. Hechos, hombres, ideas. Madrid: La esfera de los libros.

Blumenberg, Hans. 2008. La legitimación de la edad moderna. Valencia: Pre-textos.

Box, Zira. 2006. "Las tesis de la religión política y sus críticos: aproximación al debate actual». Ayer 62: 195-230. http:// revistaayer.com/sites/default/files/articulos/62-8-ayer62 MasAllaHistoriaSocial_Cabrera.pdf

Box, Zira. 2010. España, año cero: la construcción simbólica del franquismo. Madrid: Alianza.

Callahan, William. 2002. La Iglesia católica en España (1875-2002). Barcelona: Crítica.

Casanova, José. 1994. Public religions in the modern world. Chicago: The University of Chicago Press.

Casanova, José. 1999. «España: de la Iglesia estatal a la separación de Iglesia y Estado». Historia Social 35: 135-152.

Conde, Francisco Javier. 1952. Contribución a la doctrina del caudillaje. Madrid: Ediciones de la Vicesecretaría de Educación Popular.

Di Febo, Giuliana. 2002. Ritos de guerra y de victoria en la España franquista. Bilbao: Desclée e Brouwer.

22 «... la religión de los milagros y del más allá se convirtió, sin solución de continuidad, en una religión del milagro técnico, de las conquistas humanas y de la naturaleza. Una religiosidad mágica da paso a una técnica no menos mágica. Y así el siglo XX mostrará ser en sus comienzos no solo la era de la técnica sino también de una fe religiosa en ella» (Schmitt 2016, 116). Otro apunte schmittiano al respecto, a propósito de De Maistre, lo encontramos en Schmitt $(2009,50)$ : «La infalibilidad constituye a sus ojos la esencia de la decisión inapelable infalibilidad del orden espiritual y soberanía del orden político son esencialmente una misma cosa; ambos vocablos, infalibilidad y soberanía, son sinónimos naturales».
Donoso Cortés, Juan. 1854. «Ensayo sobre el catolicismo, el liberalismo y el socialismo». En Obras de Don Juan Donoso Cortés, edición de Gavino Tejado. Tomo IV. Madrid: Imprenta de Tejado.

Elorza, Antonio. 2004. «El franquismo, un proyecto de religión política». En Fascismo y franquismo cara a cara, ed. Javier Tusell, 69-83. Madrid: Biblioteca Nueva.

Fernández de la Mora, Gonzalo. 1965. El crepúsculo de las ideologías. Madrid: Ediciones Rialp.

Fouilloux, Étienne. 1995. «Iglesia católica y mundo moderno». En Religión y Sociedad en España (siglos XIX Y XX), ed. Paul Aubert, 77-89. Madrid: Colección de la Casa de Velázquez.

Gentile, Emilio. 1990. «Fascism as political religion». Journal of Contemporary History 25: 229-251.

Gentile, Emilio. 2001. Il culto del littoro. La sacralizzazione della politica nell'Italia fascista. Roma: Laterza.

González Cuevas, Pedro Carlos. 1998. Acción Española. Teología política y nacionalismo autoritario en España (1913-1936). Madrid: Tecnos.

González Cuevas, Pedro Carlos. 2000. Historia de las derechas españolas. De la llustración a nuestros días. Madrid: Biblioteca Nueva.

González Cuevas, Pedro Carlos. 2001. «Las tradiciones ideológicas de la extrema derecha española». Hispania 207, 99-142. https://doi. org/10.3989/hispania.2001.v61.i207.308

González Cuevas, Pedro Carlos. 2012. «'Punta Europa’ y ‘Atlántida': dos respuestas a la crisis de la teología política (1956-1970)». Historia y Política 28, 109-138. https://recyt.fecyt.es/index.php/Hyp/article/ view/40120/22738.

Griffin, Roger. 1993. The nature of fascism. London: Routledge.

Laboa, Juan María. 1994. La Iglesia del siglo XIX. Entre la Restauración y la Revolución. Madrid: Universidad Pontificia de Comillas.

López García, José Antonio. 1996. Estado y Derecho en el franquismo. Madrid: Centro de Estudios Constitucionales.

Marramao, Giacomo. 1998. Cielo y tierra. Genealogía de la secularización. Barcelona: Paidós.

Meier, Heinrich. 2003. Das theologisch-politische Problem. Zum Thema von Leo Strauss. Berlin: J.B. Metzler.

Meier, Heinrich. 2008. «¿Qué es la Teología Política? Introducción a un concepto controvertido". La Torre del Virrey 6: 89-93. http://www. latorredelvirrey.es/wp-content/uploads/2016/05/12.heinrich. meier.pdf

Moradiellos, Enrique. 2016. «La doctrina del caudillaje en España: legitimidad política y poder carismático durante el franquismo». Hispania 254: 789-817. https://doi.org/10.3989/hispania.2016.022

Muñoz Soro, Javier. 2006. Cuadernos para el Diálogo (1963-1976). Una historia cultural del segundo franquismo. Madrid: Marcial Pons.

Ors, Álvaro d'. 1996. «El 'Glossarium' de Carl Schmitt». En Estudios sobre Carl Schmitt, coord. Dalmacio Negro, 17-47. Madrid: Fundación Cánovas del Castillo.

Paxton, Robert. 2005. The anatomy of fascism. London: Penguin Books. Payne, Stanley. 1986. El fascismo. Madrid: Alianza.

Schmitt, Carl. 2001. «Interpretación europea de Donoso Cortés». En Carl Schmitt, teólogo de la política, ed. Héctor Orestes, 225-244. México: Fondo de Cultura Económica.

Schmitt, Carl. 2009. Teología Política. Madrid: Trotta.

Schmitt, Carl. 2016. El concepto de lo político. Madrid: Alianza.

Suárez Cortina, Manuel. 2014. Entre cirios y garrotes. Política y religión en la España contemporánea, 1808-1936. Cuenca: Ediciones de la Universidad de Castilla-La Mancha.

Villacañas, José Luis. 2000. Ramiro de Maeztu y el ideal de la burguesía en España. Madrid: Espasa.

Villacañas, José Luis. 2016. Teología política imperial y comunidad de salvación cristiana. Una genealogía de la división de poderes. Madrid: Trotta.

Villacañas, José Luis. 2017. Freud lee el Quijote. Madrid: La Huerta Grande.

Weber, Max. 1997. Sociología de la religión. Madrid: Istmo.

Zaratiegui, Jesús María. 2016. «Los orígenes ideológicos de la tecnocracia en España (1940-1962)». En La tecnocracia hispánica, ed. Antonio Cañellas, 49-80. Gijón: Trea. 